\title{
Effect of Chemical Treatment on the Morphology and Mechanical Properties of Plantain (Musa paradisiaca) Fiber
}

\author{
Patrick Ehi. Imoisili $^{1,2}$, O. B. Fadare ${ }^{3}$, A. V Popoola ${ }^{1}$, A. E. Okoronkwo ${ }^{1}$ \\ ${ }^{I}$ Chemistry Department, Federal University of Technology P.M.B 704, Akure. Nigeria \\ ${ }^{2}$ Engineering Materials Development Institute, P.M.B.611. Akure. Nigeria \\ ${ }^{3}$ National Environmental Standards and Regulations Enforcement Agency. Nigeria
}

\begin{abstract}
Natural fiber extracted from Plantain (Musa paradisiaca) fibers were treated with alkaline and potassium permanganate $\left(\mathrm{KMnO}_{4}\right)$ - acetone solution at various concentrations for different soaking time. In order to identify the effect of this chemical modification on the mechanical properties and surface morphology of the fiber, Instron testing machine and Scanning Electron Microscope (SEM) was used. Mechanical properties test results reveals that chemical treatment substantially improve the strength of treated fiber and increase it bulk density. Optimum tensile strength of 690Mpa was obtained after treatment; while Scanning Electron Microscope (SEM) micrographs indicate enhance surface roughness of treated fibres. Treated Fibres with $0.05 \% \mathrm{KMnO}_{4}$-acetone solution for $3 \mathrm{~min}(05 \mathrm{~K} 3)$ was found to the highest tensile strength, enhance uniform surface roughness, and bulk density.
\end{abstract}

Key words: Alkaline, Mechanical properties, Natural fiber, Plantain fiber, Potassium permanganate

\section{Introduction}

Natural fiber (NF) can be divided into plants, which composed of cellulose, animal or minerals which consist of proteins [1]. Natural fibers (NF) are not only biodegradable and renewable but possess some unique advantages over conventional fiber such as high modulus, high specific strength, safe manufacturing process, low cost, lightweight and high strength [2-3]. Major disadvantages of Natural Fiber in comparison with synthetic fiber are high moisture absorption, Poor wettability, incompatibility with some polymeric matrices etc [4]. To overcome these challenges, researchers have over the years suggested the use of physical and chemical treatments for surface modification as a way of overcoming these challenges and improving the properties of natural fibers [2-4]. The effect of these modification on the tensile, surface morphology, thermal behavior and structure of natural fibers has been reported by various authors [2-9].

The fiber from the plantain empty fruit bunch that are nowadays disposed as an unwanted waste, might be seen as a recyclable potential alternative to be used in polymeric matrix composite material [4-6].The plantain plant (Musa Spp) is a multivalent fiber producer, its fibers can be extracted from any part of the plant including the long leaf sheet and the pseudo-stem [5]

The use of potassium permanganate (KMn04) as chemical modification for some natural fiber has been proven to be very effective [5], as results has shown that high thermal stability [6], increase tensile strength [7], increase stiffness [7-10], changes in macromolecular and crystallographic structure were all observed after treatment [11]. Alkaline treatment of natural fiber also improves the tensile strength, fiber wetting by fibrillation, fiber-matrix adhesion due to the removal of both natural and artificial impurities, and oils covering the external surface of the fiber's cell wall, depolymerizes the native cellulose structure and exposes short length crystallites [12].

This work is aimed at evaluating the effect of chemical modification on plantain (Musa paradisiaca) fiber surface by applying some of the usual treatments for natural fibers. These actions are intended primarily on the fiber bundles, to isolating the technical fibers and removing non-structural matter from them. A subsequent objective would be evaluating the effect of these modification on extracted plantain fiber, whether the resulting fibers would obtain improve strength and stiffness as potential reinforcement for polymer matrices.

\section{Materials and Methods}

Plantain (Musa paradisiaca) pseudo stem were collected from a local farm in south west Nigeria state of Ondo after the harvest season and the fiber were extracted using water ratting methods as reported by Paridah et al [13]. The untreated fibers were designated as UT, treatment applied to fiber were reported in Table 1

\section{Alkaline Treatment of Fiber}

The extracted fibers were immersed in the solution of $1 \%$ and $3 \%$ of sodium hydroxide solution. The soaking period of fibers were varied for $1 \mathrm{hrs}$ and $4 \mathrm{hrs}$. Then the fibers were taken out from the solution, rinsed with distilled water several times and finally wash with very dilute acetic acid to remove the residual Alkaline. 
Neutrality of the fibers was checked by PH paper. The fibers were dried at room temperature for 24 hours, after which the fibers were place in an air circulating oven at $60^{\circ} \mathrm{C}$, for 6hours until the fiber gets constant weight. The fibers were designated as $1 \mathrm{~N} 1,1 \mathrm{~N} 4,3 \mathrm{~N} 1$ and $3 \mathrm{~N} 4$. The prefixes of ' $\mathrm{N}$ ' denote the concentration of the alkaline solution whereas the suffixes of ' $N$ ' represent the immersion time of the fiber in the solution in hours.

\section{Permanganate Treatment of Fiber}

The extracted fibers were treated as describe by Annapurna et.al. [10]. KMnO4-acetone solution having concentration of $0.01 \%$ and $0.05 \%$, was used to treat the fiber for a period of 1 and 3 minutes each, after which the solution was decanted and the fibers washed with acetone to remove excess solution present in the fibers. Finally, the fibers were dried at $60^{\circ} \mathrm{C}$ in a vacuum oven for $12 \mathrm{hrs}$. Untreated fiber was denoted as UT and treated fibers are designated as $01 \mathrm{~K} 101 \mathrm{~K} 3,05 \mathrm{~K} 1$ and $05 \mathrm{~K} 3$ respectively. Here $\mathrm{K}$ symbolizes to $\mathrm{KMnO} 4$ treatment. The prefixes of $\mathrm{K}$ denote the concentration of $\mathrm{KMnO}_{4}$ acetone solution i.e. 01,05 , for $0.01 \%$ and $0.05 \%$ concentrations respectively. However, the suffixes of $\mathrm{K}$ denotes the soaking time for the fibers in the solution in minutes.

Table 1: Chemical Treatment applied on plantain fiber

\begin{tabular}{|l|l|}
\hline Categories & Chemical Treatment \\
\hline UT & Untreated plantain fibers \\
\hline $1 \mathrm{~N} 1$ & $1 \%$ sodium hydroxide solution for 1 hour \\
\hline $1 \mathrm{~N} 4$ & $1 \%$ sodium hydroxide solution for 4 hour \\
\hline $3 \mathrm{~N} 1$ & $3 \%$ sodium hydroxide solution for 1 hour \\
\hline $3 \mathrm{~N} 4$ & $3 \%$ sodium hydroxide solution for 4 hour \\
\hline $01 \mathrm{~K} 1$ & $0.01 \% \mathrm{KMnO} 4-$ acetone solution for 1 minutes \\
\hline $01 \mathrm{~K} 3$ & $0.01 \% \mathrm{KMnO} 4-$ acetone solution for 3 minutes \\
\hline $05 \mathrm{~K} 1$ & $0.05 \% \mathrm{KMnO} 4$-acetone solution for 1 minutes \\
\hline $05 \mathrm{~K} 3$ & $0.05 \% \mathrm{KMnO} 4$-acetone solution for 3 minutes \\
\hline
\end{tabular}

\section{Mechanical Properties of Fiber}

Tensile tests were carried out on both untreated and treated fibers according to ASTM D 3822 at room temperature on a universal Instron testing machine model 3369, with $25 \mathrm{~N}$ as load cell full range. Fibers were tested in the as-received state at a gauge length of $10 \mathrm{~mm}$ in displacement control and at a crosshead speed of 1 $\mathrm{mm} / \mathrm{min}$. Density measurements of treated and untreated fibers were done as per ASTM D3800-99. Untreated and treated plantain fibers were examined under a Zeiss Gemini Scanning Electron Microscope (SEM) to see the effect of chemical modification on their surface properties.

\section{Results and Discussions}

The mechanical properties of treated and untreated plantain fiber are reported in Table 2. Plantain fibers exhibit the single linear elastic deformation until failure with no plastic deformation, which is typical of vegetable fibers [14]. Test results reveal that both modification has greatly improve the tensile strength, young's modulus and density of the fiber, it was also observed that permanganate treatment of $0.05 \%$ for 2 minutes gave the superior tensile strength and young's modulus. Chemical modification of plantain fiber has also resulted in reduction in crystal defect and distortion after treatments, thus lead to increase in bulk density of the fibers [10]

Table 2: Various crystallographic and physical parameters of for Untreated and $\mathrm{KMnO}_{4}$ Treated Fibers

\begin{tabular}{|c|c|c|c|c|}
\hline Sample & $\begin{array}{c}\text { Tensile Strength } \\
(\mathbf{M p a})\end{array}$ & $\begin{array}{c}\text { Young's Modulus } \\
(\mathbf{G p a})\end{array}$ & $\begin{array}{c}\text { Elongation at break } \\
(\mathbf{\%})\end{array}$ & $\begin{array}{c}\text { Density } \\
(\mathbf{g} / \mathbf{c c})\end{array}$ \\
\hline UT & 489.54 & 8.05 & 3.27 & 1.334 \\
\hline 1N1 & 538.49 & 8.87 & 3.60 & 1.362 \\
\hline 1N4 & 611.93 & 10.06 & 3.89 & 1.441 \\
\hline 3N1 & 533.60 & 8.78 & 3.56 & 1.393 \\
\hline 3N4 & 651.09 & 11.51 & 4.02 & 1.530 \\
\hline $01 \mathrm{~K} 1$ & 523.81 & 8.61 & 3.50 & 1.372 \\
\hline $01 \mathrm{~K} 3$ & 675.57 & 11.59 & 4.07 & 1.359 \\
\hline $05 \mathrm{~K} 1$ & 543.39 & 8.94 & 3.63 & 1.353 \\
\hline $05 \mathrm{~K} 3$ & 690.25 & 13.28 & 4.40 & \\
\hline
\end{tabular}

SEM micrographs of untreated and treated fiber are shown in Fig. 1(a-e).it was observed in the untreated fiber (Fig 3a), that the fiber surface was smooth, covered with waxes and other impurities. The surface roughness of the fiber was increased with increase in concentration of alkaline solution from $1 \%$ to $3 \%$ this may be due to the partial removal of hemicellulose; lignin and substantial removal of surface impurities from the fiber hence provided a rough surface to the fiber and the fibrous region became more pronounced. Maximum surface roughness for alkaline treated fiber was observed for 3N4 fiber. The SEM of permanganate treated fibers revealed that the fiber becomes rough and fibrillated, increase in $\mathrm{KMnO}_{4}$ treatment also resulted in increases of 
fiber roughness. $05 \mathrm{~K} 3$ fiber showed uniform surface roughness of the fiber. This might be due to the effective oxidation of the fiber surface when it is soaked in $0.05 \%$ of concentration of $\mathrm{KMnO} 4$ - acetone solution for 3 min which lead to the better roughness of the fiber due to the removal of lignin, waxy material along with the impurities from the fiber
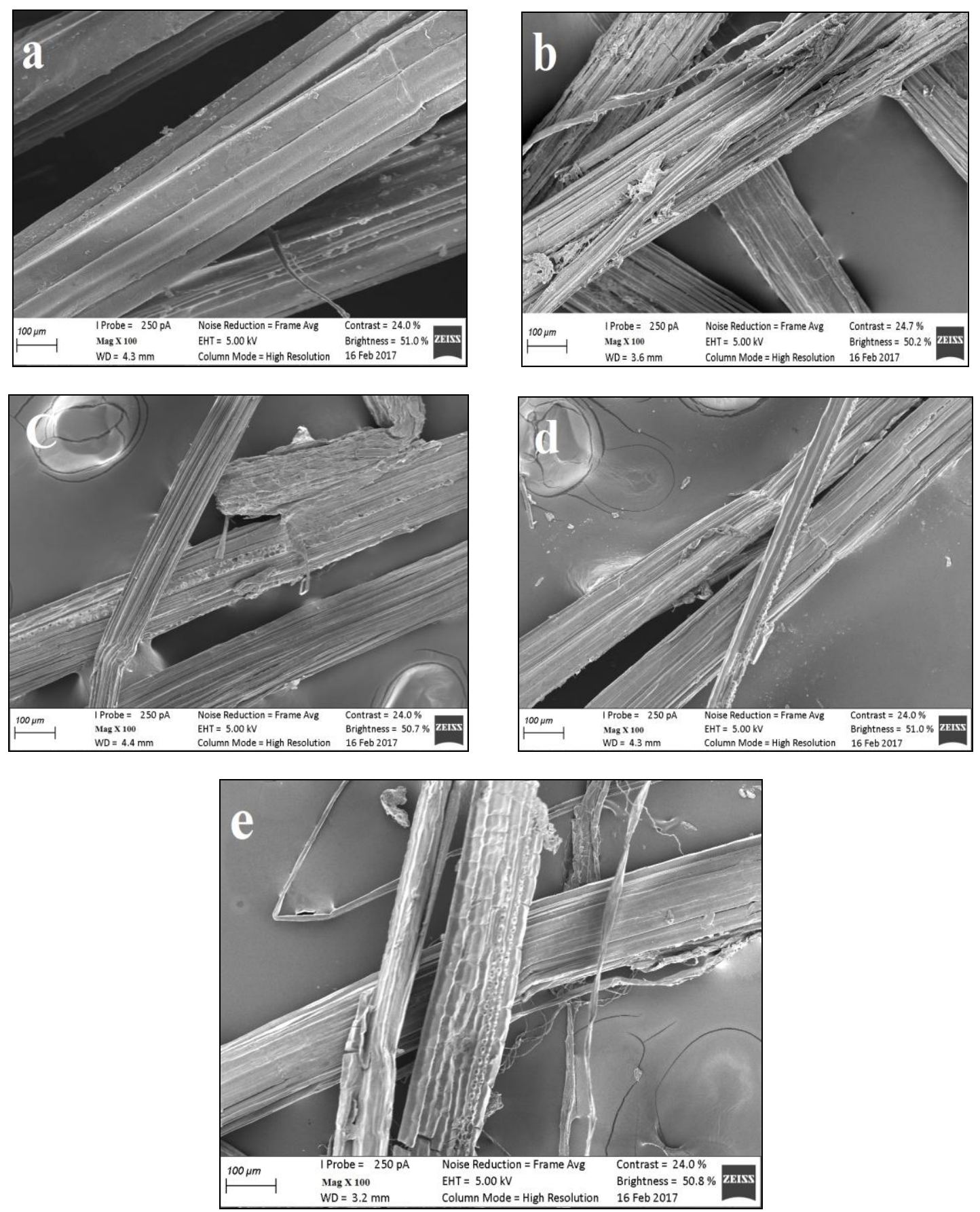

Figure 1: Longitudinal morphology of plantain fibers (a) UT (b) $1 \mathrm{~N} 4$ (c) $1 \mathrm{~N} 4$ (d) $01 \mathrm{~K} 3$ (e) $05 \mathrm{~K} 3$

\section{Conclusion}

The effect of chemical treatment on the mechanical properties of natural fiber extracted from Plantain (Musa paradisiaca) has been studies using alkaline and potassium permanganate. Result obtain shows that permanganate treated fibers has superior tensile strength, young's modulus than that of alkaline treatment. Surface morphology shows that chemical treatment increase fiber roughness by the substantial removal of surface impurities. As a general point, Chemical treatment has substantially improve the mechanical properties of Plantain (Musa paradisiaca) fiber and thus make the fiber more permeable to resin when used as composite reinforcement, 


\section{Acknowledgements}

The authors are pleased to acknowledge the kind assistance of Mrs Oyedokun Opeyemi of Research and Development Department, Engineering Materials Development Institute. Akure, Nigeria.

\section{References}

[1]. John M. J., Thomas S.: Biofibers and biocomposites. Carbohydrate Polymers 71, 2008, 343-364.

[2]. Yousif B. F., Shalwan A., Chin C. W., Ming K. C. :Flexural properties of treated and untreated kenaf/epoxy composites, Materials \& Design, 40, 2012. 378-385

[3]. Rokbi M., Osmani H., Imad A., Benseddiq N.: Effect of Chemical treatment on Flexure Properties of Natural Fiber-reinforced Polyester Composite, Procedia Engineering, 10, 2011, 2092-2097.

[4]. Bachtiar D., Sapuan S.M., Hamdan M.M. :The effect of alkaline treatment on tensile properties of sugar palm fiber reinforced epoxy composites, Materials \& Design, 29, 2008, 1285-1290.

[5]. Kalia S, Kaith B S, Kaur I.: Pretreatments of natural fibres and their application as reinforcing material in polymer composites-A review. Polymer Engineering Science, 49, 2009, 1253-1272.

[6]. Paul A, Oommen C, Joseph K, Thomas S.: The role of interface modification on thermal degradation and crystallization behaviour of composites from commingled polypropylene fiber and banana fiber. Polymer Composite, 31, 2010, 1113-1123.

[7]. Khan M. A, Hassan M., Taslima R., Mustafa A. I.: Role of pretreatment with potassium permanganate and urea on mechanical and degradable properties of photocured coir (cocos nucifera) fiber with 1, 6-hexanediol diacrylate. Journal of Applied Polymer Science, 100,2006, 4361- 4368.

[8]. Paul A., Joseph K., Thomas S.: Effect of surface treatments on the electrical properties of low-density polyethylene composites reinforced with short sisal fibres. Composite Science Technology, 51, 1997, 67-79.

[9]. F. de Andrade Silva, N. Chawla and R.D de Toledo Filho, "Tensile Behavior of High Performance Natural (sisal) Fibers," Compos Sci. Technol., 68, 2008, 3438-3443.

[10]. Wolfgang G., Martinschitz K. J, Boesecke P., Keckes J.: Structural changes during tensile testing of an all-cellulose composite by in situ synchrotron X-ray diffraction, Composite Science Technology, 66, 2006, 2639-2647.

[11]. Annapurna Patra, Dillip K. Bisoyi, Prem K. Manda, Singh A. K.: Electrical and Mechanical Properties of the Potassium Permanganate Treated Short Sisal Fiber Reinforced Epoxy Composite in Correlation to the Macromolecular Structure of the Reinforced Fiber. Journal of Applied Polymer Science. 2012

[12]. T Thamae and C Baillie, "Influence of Fiber Extraction Method, Alkali and Silane Treatment on the Interface of Agave Americana Waste HDPE Composites as Possible Roof Ceilings in Lesotho”, Compos Interf, 14, 2007, 821-836.

[13]. Paridah M. d. Tahur, Amel B. Ahmed, Syeed O. A. SaifulAzry, Zakiah Ahmed.: Retting Process of Some Bast Plant Fibres and Its Effect on Fiber Quality: a review. BioResources 6(4), 2011, 5260-5281.

[14]. De Rosa I. M, Kenny J. M., Puglia D., Santulli C., Sarasini F. Morphological and thermal characterisation of okra (Abelmoschus Esculentus) fibers as potential reinforcement in polymer composites. Compos Sci Technol 70(1), 2010, 116-122 